\title{
¿S Research Square

\section{Microstructure and Mechanical Performances Analyses on Probeless Friction Stir Spot Welds of AA6061-T6 Aluminum Sheets}

\section{Yu Guishen}

Jilin University

Chen Xin ( $\nabla$ cx@jlu.edu.cn )

Jilin University

Wu Zitao

Jilin University

Zhang Guanchen

Jilin University

\section{Chen Yixiong}

Jilin University

\section{Research Article}

Keywords: Probeless friction stir spot welding, Tensile shear failure load, Tool shape, Welding parameters optimization, Microstructure analysis, Fracture mechanism

Posted Date: October 29th, 2021

DOI: https://doi.org/10.21203/rs.3.rs-1014036/v1

License: (c) (i) This work is licensed under a Creative Commons Attribution 4.0 International License. Read Full License 


\section{Abstract}

Probeless friction stir spot welding (PFSSW) is a variation of conventional friction stir spot welding (CFSSW), which solves the keyhole defect in CFSSW welds. In this work, four types of probeless tools were designed based on helix and spiral feature: small curvature helix (involute tool, IT), large curvature helix (archimedes tool, AT), spiral line (scroll tool, ST) and no feature (flat tool, FT). AA6061-T6 sheets with a thickness of $1.5 \mathrm{~mm}$ were welded using the designed probeless welding tools. The effect of tool shapes on the microstructure and mechanical properties of friction stir spot welded AA 6061-T6 aluminum alloy sheets was investigated using different rotational speeds, plunging depths and dwell times. The Taguchi method was utilized to obtain the optimal welding parameter combination for the four tools. And, the tensile-shear mechanical properties of FSSW specimens were characterized under the optimal parameters. The results show that a basin-shaped profile appeared in the weld metallography using the groove tools. The tensile shear failure load (TSFL) of IT $(\sim 6.97 \mathrm{kN})$ was higher than that of ST $(\sim 6.49 \mathrm{kN})$, AT $(\sim 6.19 \mathrm{kN})$ and FT $(\sim 5.67 \mathrm{kN})$, sequentially. Three different fracture modes, interfacial fracture, plug fracture and mixed-mode fracture were observed in the tensile-shear tests of weld specimens.

\section{Introduction}

In the last years, a critical trend in automotive manufacturing is to reduce fuel consumption and greenhouse gas emissions [1, 2]. The replacement of traditional iron-based alloys with lightweight materials such as aluminum and magnesium alloys is one way to achieve this target. Aluminum is considered an ideal alternative material for automotive body structures due to its low density, high strength-to-mass ratio and strong damping properties [3]. There are 4,000 6,000 spot welds in the bodyin-white $[4,5]$. High-strength and reliable welds are significant to automotive safety [6]. Resistance spot welding (RSW) is the most used joining process in the automotive industry which has been widely used for spot joining of low carbon, high strength and coated steel $[7,8]$. However, there are welding defects such as thermal cracking, porosity and slagging in the RSW process for aluminum alloy welds, which decreases the mechanical properties of the joint $[9,10]$.

Friction stir spot welding (FSSW) is a new solid-phase joining technology developed by the GKSS plant in Germany [11]. Mazda Motor Corporation first applied the FSSW process to the rear door of the 2003 RX-8 [9]. FSSW process is considered a promising way to weld aluminum alloys because it effectively avoids defects in the conventional fusion welding technology $[12,13]$. The FSSW process is similar to friction stir welding (FSW), except for no transverse movement of the welding tool [14]. The biggest limitation of conventional FSSW (CFSSW) is the keyhole, which is not only aesthetically undesirable but also decreases the bonding area of the weld $[15,16]$. In order to solve this issue, engineers invented refill friction stir spot welding (RFSSW) and probeless friction stir spot welding (PFSSW). The RFSSW process squeezes the extrusive material into the weld by a complex movement with a probe, a sleeve and a clamping ring [17]. There is no keyhole appeared in the weld after the welding process [18]. However, the RFSSW process is not widely used in industry due to the complexity of the manufacturing equipment [19, 
20]. As shown in Figure 1, the PFSSW process can be divided into three stages. In the plunging stage, the welding tool is rotating and plunging into the base material to a predefined depth (Figure 1 (a)). Subsequently, the tool dwelling and generating frictional heats with the base material (Figure $1(b)$ ). This process causes plastic flows of material around the welding tool and creates a solid bonding between the surfaces of the upper and lower sheets. Finally, the welding tool is drawn out and complete the welding process (Figure 1 (c)) [21].

Extensive research has explored the PFSSW through the interaction among process, microstructure and mechanical properties. Li et al. [22] developed a phenomenological model for the TSFL value of PFSSW welds with stirring zone width (SZW), stirring zone angle (SZA) and hook angle (HA) for AA2198-T6 aluminum alloy. They pointed out that the failure load of the joint is mainly affected by the HA. When the $\mathrm{HA}$ is around $90^{\circ}$, the failure load reaches the maximum. Yazdi et al. ${ }^{[23]}$ compared the tensile-shear mechanical performances of PFSSW and conventional FSSW (CFSSW) welds. The results show that the failure load of PFSSW was $52.9 \%$ higher than that of CFSSW. Chu et al. ${ }^{[24]}$ investigated the effects of surface conditions on the mechanical properties of PFSSW welds. The results showed that the metallurgical connection was improved since surface grinding increased the surface roughness and local abrasion of the weld. On the other hand, some scholars studied the material flow states for PFSSW. Yang et al. [19] explored the material flow patterns of PFSSW welding using the coupled Lagrangian-Eulerian method, and the results are shown in Figure 2. First, the plasticized material on the top surface flows

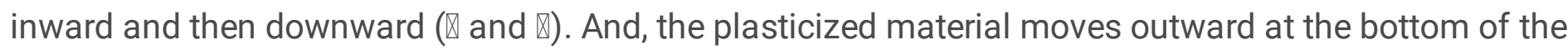
SZ ( $)$. At the same time, the material is extruded from the lower sheet and flows upward. Finally, parts of the plasticized material flow toward the shoulder outside, forming flash (『). In the open literature, a large number of studies compared the effect of shoulder shapes on the mechanical performances of the weld at the same welding parameters. Chu et al. [25] compared the temperature field and material flow for 7075-T651 aluminum alloy in different shoulder shapes. They pointed out that the grooves mainly affect the material flow and have little influence on heat generation. Ahmet [26] compared the mechanical properties of AZ31B joints with "scrolled", "knurled", "ridged", "grooved" and "concentric" shoulders at the same welding parameters. The results show that the "ridged" tool obtained the optimal tensile shear and bending performances. Nevertheless, the comparative study on the optimal performances of PFSSW joints with different shoulder shapes has not been fully reported.

The aim of this work was to investigate the influence of shoulder shapes on the microstructure and mechanical performances of the PFSSW process for AA6061-T6, under the optimal welding parameters. Three welding tools were designed according to the commonly used spiral and helix features. An orthogonal experiment matrix was used to analyze the effects of welding parameters on the TSFL value of PFSSW welds. Then, the optimal parameters combinations for the four shoulder shapes were selected according to the Taguchi method. Finally, the typical fracture mechanisms of welds were also investigated in detail.

\section{Material And Methods}


AA6061 aluminum alloy has been widely used in automotive stampings due to its excellent machinability and weldability [27]. In this study, the commonly used AA6061-T6 sheets for automobile bodies with a thickness of $1.5 \mathrm{~mm}$ were studied. The nominal chemical composition of the base metal is $0.99 \mathrm{Mg}$ 0.66Si-0.23Fe-0.23Cu-0.12Zn-0.1 Mn-0.1 Cr (wt\%). According to guidelines given in GB/T 228.1-2010, the mechanical properties of the base metal were measured and the results are illustrated in Table 1 [28]. The sheets were cut to predetermined sizes by laser cutting along the rolling direction. Tensile-shear samples were made of two $40 \times 125 \mathrm{~mm}$ sheets with an overlapping area of $40 \times 40 \mathrm{~mm}$ (Figure 3). The manufacturing of PFSSW welds was conducted using a CNC vertical machining centre (M-V6T, Manulife CNC Equipment Co., Ltd., Guangzhou, China), as shown in Figure 4(a). Prior to welding, the surface of the base material in the overlap area was polished with an angle grinder equipped with a wire brush to remove the oxide layer. During the welding process, sheets in tensile-shear configurations were rigidly fixed by a specially designed welding fixture (Figure 4(b)). The probeless welding tool is made of $\mathrm{H} 13$ tool steel with a $15 \mathrm{~mm}$ shoulder diameter, as presented in Figure 5(a). Four welding tools were involved (FT, AT, IT and ST), based on features of the helix and spiral line, as exhibited in Figure $5(\mathrm{~b}) \sim(e)[25,29]$.

Table 1

Mechanical properties of the used AA 6061-T6 alloy.

\begin{tabular}{|lllll|}
\hline $\begin{array}{l}\text { Young's } \\
\text { Modulus (GPa) }\end{array}$ & $\begin{array}{l}\text { Yield } \\
\text { Strength } \\
(\mathrm{MPa})\end{array}$ & $\begin{array}{l}\text { Ultimate Tensile } \\
\text { Strength (MPa) }\end{array}$ & $\begin{array}{l}\text { Elongation at } \mathbf{5 0 ~} \mathrm{mm} \\
\text { Gauge (\%) }\end{array}$ & $\begin{array}{l}\text { Section } \\
\text { Shrinkage (\%) }\end{array}$ \\
\hline 68.26 & 299.31 & 388.82 & 12.93 & 9.06 \\
\hline
\end{tabular}

The TSFL value of welds was measured using a computer-controlled universal testing machine (WDW3100 ) at a loading rate of $5 \mathrm{~mm} / \mathrm{min}$. During the stretching process, spacers were placed on two chucks to minimize the effect of bending moment on the failure loads, as shown in Figure 6. Each group was tested three times to decrease experimental errors. The fracture characteristics of the weld samples were analyzed by a scanning electron microscope (SEM, JSM-IT500A). The metallographic specimens were cut along the centre of the weld. Then, the specimens were mechanically ground, polished, and etched by Keller's reagent ( $2 \mathrm{ml} \mathrm{HF}, 3 \mathrm{ml} \mathrm{HCl}, 5 \mathrm{ml} \mathrm{HNO}_{3}$ and $190 \mathrm{ml} \mathrm{H}_{2} \mathrm{O}$ ) for approximately four minutes. The metallographic structure of weld samples was observed by an optical microscope (OM, Imager-M2m).

In this study, the Taguchi method was adopted to optimize the PFSSW parameters of AA6061-T6 aluminum alloy for the four shoulder shapes. The appropriate experimental matrix was selected based on the total freedom degrees. The three process parameters (RS, PD and DT) were set in four levels. According to the preliminary experimental results, the PFSSW welds of AA6061-T6 aluminum alloy showed poor joint strength at the rotation speed lower than $2500 \mathrm{rpm}$, the plunging depth lower than 0.3 $\mathrm{mm}$, and the dwell time lower than $4 \mathrm{~s}$. Furthermore, severe thermal deformation and flash of the weld occurred at the rotation speed higher than $4000 \mathrm{rpm}$, the plunging depth higher than $0.9 \mathrm{~mm}$ and the dwell time higher than $10 \mathrm{~s}$. In this work, the four levels of welding parameters are exhibited in Table 2. The $L_{16}\left(4^{3}\right)$ orthogonal matrix was selected, and the detailed parameter combinations are listed in Table 
3. In data analysis, the signal-to-noise ratio $(\mathrm{S} / \mathrm{N})$ was used to control the variability of the response. The $\mathrm{S} / \mathrm{N}$ of the TSFL value for the welds was analyzed according to the principle of "the larger-the better", and the calculation formula is defined as [30,31]:

$S / N=-10 \log \left(\frac{1}{n} \sum_{i=1}^{n} \frac{1}{y_{i}^{2}}\right)$,

where, $n$ is the number of tests and, $y_{i}$ is the observed experimental data for the $i$-th TSFL value. It can be seen that a higher $\mathrm{S} / \mathrm{N}$ value indicates a better tensile-shear performance of PFSSW welds.

Table 2

Welding parameters and their levels.

\begin{tabular}{|llllll|}
\hline Process factors & Notation & \multicolumn{3}{l}{ Levels } & \\
\cline { 3 - 6 } & & $\mathbf{1}$ & $\mathbf{2}$ & $\mathbf{3}$ & $\mathbf{4}$ \\
\hline Shoulder shape (-) & SP & FT & AT & IT & ST \\
\hline Rotation speed (rpm) & RS & 2500 & 3000 & 3500 & 4000 \\
\hline Plunge depth (mm) & PD & 0.3 & 0.5 & 0.7 & 0.9 \\
\hline Dwell time (s) & DT & 3 & 5 & 7 & 9 \\
\hline
\end{tabular}

\section{Results And Discussion}

\subsection{Welds microstructure}

The metallographic structures of welds made by the four shoulder shapes are shown in Figure 7. There are no grooves on the FT, which decreased the stirring effects in the welding process (Figure 5(a)). Therefore, there is no typical basin-shaped profile in the FT joint (Figure 7 (a)). Similar metallographic results were also found by Dimiterios et al [29]. According to the microstructure, AT, IT and ST welds were divided into three characteristic zones (SZ, HAZ and TMAZ). Chu et al. [21] noted that refined equiaxed grains were formed in the $S Z$, due to high temperature and dynamic recrystallization processes. HAZ experienced a moderate welding thermal cycle and the grain size was slightly larger than SZ. The TMAZ grains experienced severe deformations and partial recrystallization, owing to frictional heat and plastic deformation during the welding process. The highest SZW value was obtained in the ST weld $(\sim 13.6$ $\mathrm{mm})$, the smallest in the AT weld $(\sim 7.83 \mathrm{~mm})$ and the middle in the IT weld $(\sim 11.3 \mathrm{~mm})$. Moreover, the SZD value of IT and ST joints $(\sim 1.6 \mathrm{~mm})$ is slightly higher than that of AT joints $(\sim 1.51 \mathrm{~mm})$ under the selected welding parameters. As for the flash edge height, the FEH value of the ST weld $(\sim 1.27 \mathrm{~mm})$ is significantly lower than that of the FT, AT and IT weld.

\subsection{Optimizing the welding parameters}


The PFSSW welds were manufactured for the four shoulder shapes according to the orthogonal matrix, and the TSFL values of the welds were obtained from the tensile-shear test. The tests were repeated three times for each group to reduce the test error, and the results are given in Table 3 . The mean TSFL values and $\mathrm{S} / \mathrm{N}$ ratios of PFSSW welds for the four shoulder shapes were obtained by the Taguchi method (Figure 8). The TSFL mean represents the arithmetic mean of the response (TSFL) of the welding parameters at each level, and the $\mathrm{S} / \mathrm{N}$ ratio represents the deviation (noise) of the response from its mean (signal). The $\mathrm{S} / \mathrm{N}$ ratio was optimized the tensile-shear performance of PFSSW welds in a "larger the better" method. Within the predefined ranges of welding parameters, RS, PD and DT have significant effects on the TSFL value of the joint, which can be seen in Figure 8. The optimal combination of welding parameters in four shoulder shapes was obtained from Taguchi design results ( $F T: R_{2} P_{3} D_{3}$, AT: $\mathrm{RS}_{4} \mathrm{PD}_{3} \mathrm{DT} \mathrm{T}_{2}, \mathrm{IT}: \mathrm{RS}_{3} \mathrm{PD}_{2} \mathrm{DT}_{2}$, and ST: $\mathrm{RS}_{3} \mathrm{PD}_{2} \mathrm{DT}_{2}$ ). 
Table 3

Taguchi design matrix and experiment results.

\begin{tabular}{|c|c|c|c|c|c|c|c|c|c|c|}
\hline \multirow[t]{2}{*}{ No. } & \multicolumn{3}{|c|}{ Code value } & \multicolumn{3}{|c|}{ Actual value } & \multicolumn{4}{|c|}{ Average TSFL (kN) } \\
\hline & RS & PD & DT & $\begin{array}{l}\text { RS } \\
\text { (rpm) }\end{array}$ & $\begin{array}{l}\text { PD } \\
(\mathrm{mm})\end{array}$ & $\begin{array}{l}\text { DT } \\
\text { (s) }\end{array}$ & FT & AT & IT & ST \\
\hline $1^{\#}$ & 1 & 1 & 1 & 2500 & 0.3 & 4 & 2.47 & 3.45 & 4.02 & 2.77 \\
\hline $2^{\#}$ & 1 & 2 & 2 & 2500 & 0.5 & 6 & 4.56 & 5.16 & 6.72 & 5.52 \\
\hline $3^{\#}$ & 1 & 3 & 3 & 2500 & 0.7 & 8 & 5.55 & 5.13 & 5.06 & 5.14 \\
\hline $4^{\#}$ & 1 & 4 & 4 & 2500 & 0.9 & 10 & 4.55 & 4.77 & 5.32 & 4.54 \\
\hline $5^{\#}$ & 2 & 1 & 2 & 3000 & 0.3 & 6 & 3.62 & 4.61 & 5.24 & 6.10 \\
\hline $6^{\#}$ & 2 & 2 & 1 & 3000 & 0.5 & 4 & 5.02 & 4.58 & 6.76 & 5.57 \\
\hline $7^{\#}$ & 2 & 3 & 4 & 3000 & 0.7 & 10 & 5.85 & 5.14 & 6.34 & 5.36 \\
\hline $8^{\#}$ & 2 & 4 & 3 & 3000 & 0.9 & 8 & 4.86 & 5.19 & 5.72 & 4.59 \\
\hline $9^{\#}$ & 3 & 1 & 3 & 3500 & 0.3 & 8 & 3.90 & 4.63 & 5.33 & 6.15 \\
\hline $10^{\#}$ & 3 & 2 & 4 & 3500 & 0.5 & 10 & 4.97 & 4.98 & 6.35 & 6.20 \\
\hline $11^{\#}$ & 3 & 3 & 1 & 3500 & 0.7 & 4 & 5.34 & 5.51 & 6.43 & 5.87 \\
\hline $12^{\#}$ & 3 & 4 & 2 & 3500 & 0.9 & 6 & 4.91 & 5.40 & 6.17 & 5.42 \\
\hline $13^{\#}$ & 4 & 1 & 4 & 4000 & 0.3 & 10 & 2.81 & 4.94 & 4.20 & 5.85 \\
\hline $14^{\#}$ & 4 & 2 & 3 & 4000 & 0.5 & 8 & 5.13 & 5.34 & 6.64 & 6.40 \\
\hline $15^{\#}$ & 4 & 3 & 2 & 4000 & 0.7 & 6 & 5.84 & 5.93 & 6.32 & 5.84 \\
\hline $16^{\#}$ & 4 & 4 & 1 & 4000 & 0.9 & 4 & 5.23 & 5.29 & 6.19 & 5.34 \\
\hline
\end{tabular}

Load-displacement curves under the optimal welding parameters for the four welding tools are given in Figure 9(a) (d). Figure 9(e) compares the TSFL values. The shoulder stirring effects of the helix line with small curvature (IT) are better than that of the spiral line (ST) and the helix line with large curvature (AT). The results show that the IT joints obtained the highest TSFL $(\sim 6.97 \mathrm{kN})$ higher than that of ST $(\sim 6.49 \mathrm{kN})$ and AT $(\sim 6.19 \mathrm{kN})$. The lowest TSFL value was obtained from FT $(\sim 5.67 \mathrm{kN})$ due to the nongrooves on the FT shoulder, which decreases the material flow in the welding process. The optimal levels of welding parameters and the TSFL results predicted based on the Taguchi method are presented in Table 4. The average TSFL values were obtained from the tensile-shear tests under the optimum welding 
parameters and compared with the predicted values. The errors were less than $5.81 \%$, which indicates the reliability of the optimization method.

Table 4

Verification of the optimized results.

\begin{tabular}{|c|c|c|c|c|c|c|c|}
\hline \multirow[t]{2}{*}{ SP } & \multirow[t]{2}{*}{ Setting level } & \multirow[t]{2}{*}{ RS (rpm) } & \multirow[t]{2}{*}{ PD (mm) } & \multirow[t]{2}{*}{ DT (s) } & \multicolumn{2}{|l|}{ TSFL (kN) } & \multirow[t]{2}{*}{ Error \% } \\
\hline & & & & & Predicted & Experimental & \\
\hline FT & $\mathrm{RS}_{2} \mathrm{PD}_{3} \mathrm{DT}_{3}$ & 3000 & 0.7 & 8 & 6.02 & 5.67 & 5.81 \\
\hline AT & $\mathrm{RS}_{4} \mathrm{PD}_{3} \mathrm{DT}_{2}$ & 4000 & 0.7 & 6 & 6.07 & 6.19 & 1.98 \\
\hline IT & $\mathrm{RS}_{3} \mathrm{PD}_{2} \mathrm{DT}_{2}$ & 3500 & 0.5 & 6 & 7.20 & 6.97 & 3.19 \\
\hline ST & $\mathrm{RS}_{3} \mathrm{PD}_{2} \mathrm{DT}_{2}$ & 3500 & 0.5 & 6 & 6.72 & 6.49 & 3.42 \\
\hline
\end{tabular}

\subsection{Fracture mode analysis}

In general, PFSSW welds show three failure modes in the tensile-shear tests, namely interfacial fracture (mode I), plug fracture (mode II) and mixed-mode fracture (mode III). In mode I, cracks nucleate from the bonding interface of the upper and lower sheets and propagate along the interface. The upper and lower sheets were separated eventually, as shown in Figure 10 (a). Yang et al. [32] pointed that the crack extends from the edge of the hook to the upper sheet surface when the hook angle changes from obtuse to acute. Eventually, the weld nugget is pulled out from the upper sheet (mode II), as shown schematically in Figure 10 (b). In mode III, the weld nugget is partially extracted and split into two parts along the bonding interface of the upper and lower sheets (Figure 10 (c)).

The macroscopic fracture morphology in mode I is shown in Figure 11 (a) and (b). The bonding surface of the weld is sheared off. Due to the stirring effects of the tool shoulder, the spiral marks appear in the weld fracture surface. Figure 11 (c) and (d) show SEM micrographs at the upper sheet of the weld. There are small and dispersed shear dimples in the weld nugget, indicating the sound bonding quality.

Moreover, the region near the centre of the weld contains smaller dimples, which are results from severe stirring effects and dynamic recrystallization in SZ. Figure 11 (e) and (f) show SEM micrographs of the weld fracture surface at the edge of the lower sheet. The fracture morphologies on the top and right side appear the quasi-cleavage fracture features, which indicates that the weld edge is in a weak bonding condition.

The macroscopic fracture morphology of mode II is shown in Figure 12 (a) and (b). The crack sprouts from the hook tip and extends along the edge of the weld nugget to the upper sheet surface. Eventually, the weld nugget is pulled out and entirely attached to the lower sheet (Figure 12 (b)). The tear ridges and uneven distribution of the cleavage surface are illustrated in Figure 12 (c) and (d), which indicates the hook defect is a weak bonding region. 
Yang et al. [32] pointed that the mixed fracture mode occurs at a hook angle around $90^{\circ}$. On one side of the weld, the crack first extends from the hook tip to the upper sheet surface, which is similar to the fracture characteristics of mode II. Subsequently, the crack expands along the circumferential direction of the weld nugget under tensile-shear loads. Ultimately, the weld nugget was partially extracted, as shown in Figure 13 (a). On the other side of the weld, the hook crack extends along the bonding surface and eventually separates the weld, which is similar to mode I (Figure $13(b)$ ). There are small equiaxed dimples in the fracture surface of the weld, indicating the weld is in a sound bonding condition (Figure 13 (c) and (d)). The centre region of the weld contains smaller equiaxed dimples due to dynamic recrystallization in the welding process. Figure 13 (e) and (f) show SEM micrographs of the weld fracture surface on the lower plate. The margin regions at the right and bottom sides exhibit irregularly distributed cleavage surfaces, indicating the hook defect is in a weak bonding condition.

\section{Conclusion}

In this work, $1.5 \mathrm{~mm}$ thick AA6061-T6 aluminum alloy sheets were welded by PFSSW. The effect of welding parameters and tool shoulders on the microstructure and the mechanical performances of the welds were investigated. Taguchi experimental method was used to determine the optimum welding parameters for the four shoulder shapes. Based on the results obtained in the present study, the following can be drawn:

1. The shoulder groove enhances the stirring effect during the welding process, which leads to a typical basin-shaped profile exhibited on AT, IT and ST joints.

2. Taguchi orthogonal array, $\mathrm{S} / \mathrm{N}$ ratio and mean effects plots were used to optimize the TSFL value of welds. The verification experiments were conducted, with a maximum error is $5.81 \%$. The optimal combinations of welding parameters for the four shoulder shapes are $R_{2} \mathrm{PD}_{3} \mathrm{DT} \mathrm{T}_{3}(\mathrm{FT}), \mathrm{RS}_{4} \mathrm{PD}_{3} \mathrm{DT} \mathrm{T}_{2}$ (AT), $\mathrm{RS}_{3} \mathrm{PD}_{2} \mathrm{DT}_{2}(\mathrm{IT})$, and $\mathrm{RS}_{3} \mathrm{PD}_{2} \mathrm{DT}_{2}(\mathrm{ST})$.

3. There is an obvious effect of shoulder shapes on the tensile-shear performances of PFSSW joints. The TSFL value for shoulders with the small curvature helix (IT, 6.97 kN) is higher than that of the spiral line (ST, 6.49 kN), the large curvature helix (AT, 6.19 kN) and no feature (FT, 5.67 kN), sequentially.

4. The macrographs of failure samples exhibited three types of fracture modes, interfacial fracture, plug fracture and mixed-mode fracture. Since severe stirring effects and dynamic recrystallization occurred in SZ, the fracture exhibited finer dimples. The hook defect is a weak connection region that exhibits a quasi-cleavage fracture mode.

\section{References}

[1] MirHashemi SM, Amadeh A, Khodabakhshi F. Effects of SiC nanoparticles on the dissimilar friction stir weldability of low-density polyethylene (LDPE) and AA7075 aluminum alloy. J Mater Res Technol 2021;13:449-462. https://doi.org/10.1016/j.jmrt.2021.04.094. 
[2] Yu G, Chen X, Wu Z. Mechanical performance optimization and microstructure analysis of similar thin AA6061-T6 sheets produced by swept friction stir spot welding. Int J Adv Manuf Technol 2021. https://doi.org/10.1007/s00170-021-07387-7.

[3] Paidar M, Vignesh RV, Moharrami A, Ojo 00, Jafari A, Sadreddini S. Development and characterization of dissimilar joint between AA2024-T3 and AA6061-T6 by modified friction stir clinching process. Vacuum. 2020;176:109298. https://doi.org/10.1016/j.vacuum.2020.109298.

[4] Zhou L, Xia Y, Shen Y, Haselhuhn AS, Wegner DM, Li Y, et al. Comparative study on resistance and displacement based adaptive output tracking control strategies for resistance spot welding. J Manuf Processes 2021;63:98-108. https://doi.org/10.1016/j.jmapro.2020.03.061.

[5] Ferreira AC, Campanelli LC, Suhuddin UFH, de Alcantara NG, dos Santos JF. Investigation of internal defects and premature fracture of dissimilar refill friction stir spot welds of AA5754 and AA6061. Int J Adv Manuf Technol 2020;106:3523-3531. https://doi.org/10.1007/s00170-019-04819-3.

[6] Zhang B, Chen X, Pan K, Yang C. J-integral based correlation evaluation between microstructure and mechanical strength for FSSW joints made of automotive aluminum alloys. J Manuf Processes 2019;44:62-71. https://doi.org/10.1016/j.jmapro.2019.05.039.

[7] Hu S, Haselhuhn AS, Ma Y, Li Y, Carlson BE, Lin Z. Influencing mechanism of inherent aluminum oxide film on coach peel performance of baked Al-Steel RSW. Mater Des 2021;197:109250. https://doi.org/10.1016/j.matdes.2020.109250.

[8] Lu Y, Sage DD, Fink C, Zhang W. Dissimilar metal joining of aluminium to zinc-coated steel by ultrasonic plus resistance spot welding-microstructure and mechanical properties. Sci Technol Weld Joi 2020;25:218-227. https://doi.org/10.1080/13621718.2019.1667051.

[9] Li Z, Gao S, Ji S, Yue Y, Chai P. Effect of rotational speed on microstructure and mechanical properties of refill friction stir spot welded 2024 Al alloy. J Mater Eng Perform 2016;25:1673-1682. https://doi.org/10.1007/s11665-016-1999-2.

[10] Zou Y, Li W, Chu Q, Shen Z, Wang F, Tang H, et al. The impact of macro/microstructure features on the mechanical properties of refill friction stir spot-welded joints of AA2219 alloy with a large thickness ratio. Int J Adv Manuf Technol 2021;112:3093-3103. https://doi.org/10.1007/s00170-020-06504-2.

[11] Zlatanovic DL, Balos S, Bergmann JP, Kohler T, Gratzel M, Sidjanin L, et al. An experimental study on lap joining of multiple sheets of aluminium alloy (AA 5754) using friction stir spot welding. Int J Adv Manuf Technol 2020;107:3093-3107. https://doi.org/10.1007/s00170-020-05214-z.

[12] Wang X, Morisada Y, Fujii H. High-strength Fe/Al dissimilar joint with uniform nanometer-sized intermetallic compound layer and mechanical interlock formed by adjustable probes during double-sided 
friction stir spot welding. Mater Sci Eng, A 2021;809:141005.

https://doi.org/10.1016/j.msea.2021.141005.

[13] Zlatanovic DL, Balos S, Bergmann JP, Rasche S, Zavasnik J, Panchal V, et al. In-depth microscopic characterisation of the weld faying interface revealing stress-induced metallurgical transformations during friction stir spot welding. Int J Mach Tools Manuf 2021;164:103716.

https://doi.org/10.1016/j.ijmachtools.2021.103716.

[14] Li M, Zhang C, Wang D, Zhou L, Wellmann D, Tian Y. Friction stir spot welding of aluminum and copper: a review. Materials 2020;13:156. https://doi.org/10.3390/ma13010156.

[15] Cao JY, Zhang CC, Xing YF, Wang M. Pin plunging reinforced refill friction stir spot welding of Alclad 2219 to 7075 alloy. J Mater Process Technol 2020;284:116760.

https://doi.org/10.1016/j.jmatprotec.2020.116760.

[16] Mehrez S, Paidar M, Cooke K, Vignesh RV, Ojo OO, Babaei B. A comparative study on weld characteristics of AA5083-H112 to AA6061-T6 sheets produced by MFSC and FSSW processes. Vacuum. 2021;190:110298. https://doi.org/10.1016/j.vacuum.2021.110298.

[17] Zhang HF, Zhou L, Li GH, Tang YT, Li WL, Wang R. Prediction and validation of temperature distribution and material flow during refill friction stir spot welding of AZ91D magnesium alloy. Sci Technol Weld Joi 2021;26:153-160. https://doi.org/10.1080/13621718.2020.1864864.

[18] Zhang C, Cao J, Shirzadi AA. Refill Friction Stir Spot Welding (Refill FSSW) of magnesium lithium alloys: effects of air and argon cooling. Sci Technol Weld Joi 2021;45:17784-17804. https://doi.org/10.1080/13621718.2021.1884801.

[19] Yang X, Feng W, Li W, Xu Y, Chu Q, Ma T, et al. Numerical modelling and experimental investigation of thermal and material flow in probeless friction stir spot welding process of Al 2198-T8. Sci Technol Weld Joi 2018;23:704-714. https://doi.org/10.1080/13621718.2018.1469832.

[20] Yang XW, Fend WY, Li WY, Dong XR, Xu YX, Chu Q, et al. Microstructure and properties of probeless friction stir spot welding of AZ31 magnesium alloy joints. T NONFERR METAL SOC 2019;29:2300-2309. https://doi.org/10.1016/s1003-6326(19)65136-8.

[21] Chu Q, Li WY, Yang XW, Shen JJ, Vairis A, Feng WY, et al. Microstructure and mechanical optimization of probeless friction stir spot welded joint of an Al-Li alloy. J Mater Sci Technol 2018;34:1739-1746. https://doi.org/10.1016/j.jmst.2018.03.009.

[22] Li WY, Chu Q, Yang XW, Shen JJ, Vairis A, Wang WB. Microstructure and morphology evolution of probeless friction stir spot welded joints of aluminum alloy. J Mater Process Technol 2018;252:69-80. https://doi.org/10.1016/j.jmatprotec.2017.09.003. 
[23] Yazdi SR, Beidokhti B, Haddad-Sabzevar M. Pinless tool for FSSW of AA 6061-T6 aluminum alloy. J Mater Process Technol 2019;267:44-51. https://doi.org/10.1016/j.jmatprotec.2018.12.005.

[24] Chu Q, Yang XW, Li WY, Lu T, Zhang Y, Vairis A, et al. Impact of surface state in probeless friction stir spot welding of an Al-Li alloy. Sci Technol Weld Joi 2019;24:200-208.

https://doi.org/10.1080/13621718.2018.1517966.

[25] Chu X, Yin M, Gao J, Wang X, Wang Y. Effects of shoulder geometry on microstructures and mechanical properties of probeless friction stir spot welded aluminum 7075-T651 sheets. Metals 2020;10:1605. https://doi.org/10.3390/met10121605.

[26] Atak A. Impact of pinless stirring tools with different shoulder profile designs on friction stir spot welded joints. J Mech Sci Technol 2020;3735-3743. https://doi.org/10.1007/s12206-020-0825-9.

[27] Samal P, Vundavilli PR, Meher A, Mahapatra MM. Recent progress in aluminum metal matrix composites: A review on processing, mechanical and wear properties. J Manuf Processes 2020;59:131152. https://doi.org/10.1016/j.jmapro.2020.09.010.

[28] Metallic materials-Tensile testing-Part 1: Method of test at room temperature, in, Standards Press of China, Beijing, 2010.

[29] Bakavos D, Chen Y, Babout L, Prangnell P. Material Interactions in a Novel Pinless Tool Approach to Friction Stir Spot Welding Thin Aluminum Sheet. Metall Mater Trans A 2011;42:1266-1282. https://doi.org/10.1007/s11661-010-0514-x.

[30] Peace GS, Taguchi methods, Addison Wesley Publishing Company, New York, 1993.

[31] Suresh S, Venkatesan K, Natarajan E, Rajesh S. Performance analysis of nano silicon carbide reinforced swept friction stir spot weld joint in AA6061-T6 alloy. Silicon 2021;13:3399-3412. https://doi.org/10.1007/s12633-020-00751-4.

[32] Yang X, Fend W, Li W, Dong X, Xu Y, Chu Q, et al. Microstructure and properties of probeless friction stir spot welding of AZ31 magnesium alloy joints. T NONFERR METAL SOC 2019;29:2300-2309. https://doi.org/10.1016/s1003-6326(19)65136-8.

\section{Figures}
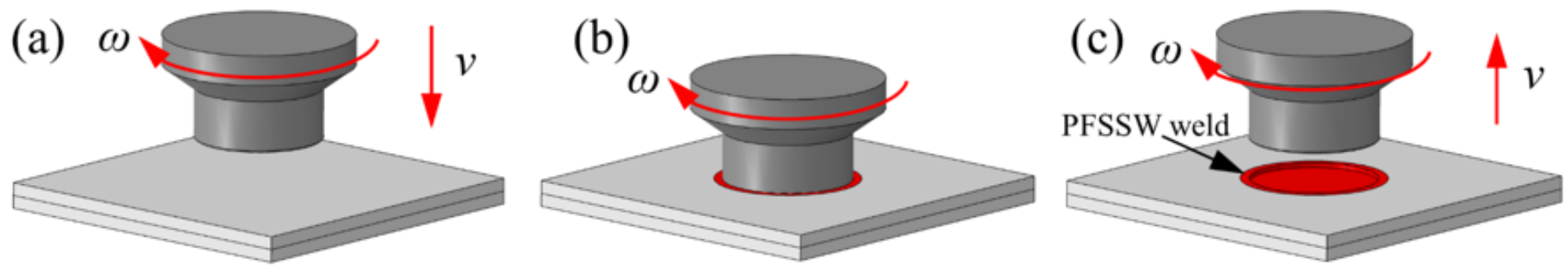
Figure 1

Schematic diagram of the PFSSW process: (a) plunging, (b) stirring and (c) drawing out.

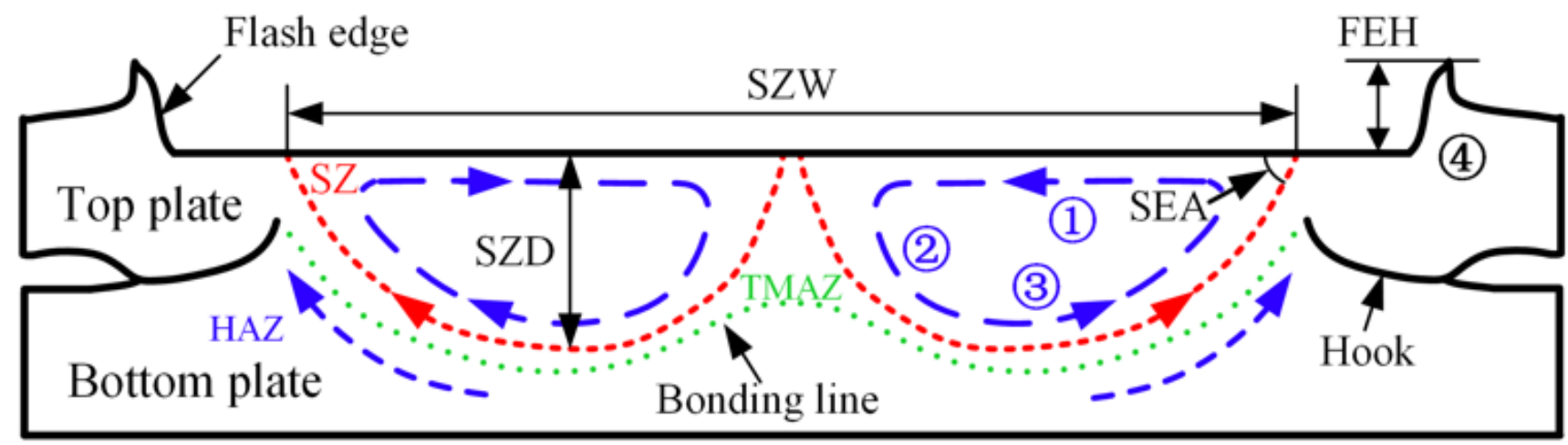

SZ- stir zone; TMAZ- thermal-mechanical affected zone; HAZ- heat affected zone; SZW- stir zone width; SZD- stir zone depth; SEA- stir zone edge angle; FEH- flash edge height

Figure 2

Diagram of the material flow and characteristic zones in the welding process.

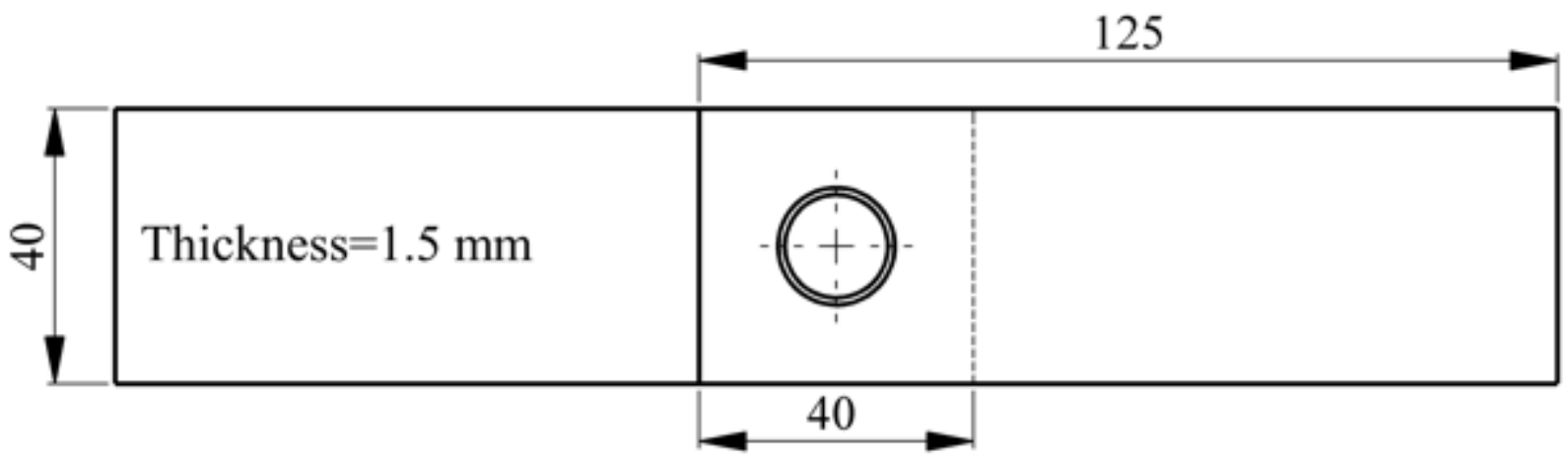

Figure 3

Schematic diagram and dimensions of the tensile-shear specimen ( $\mathrm{mm})$.
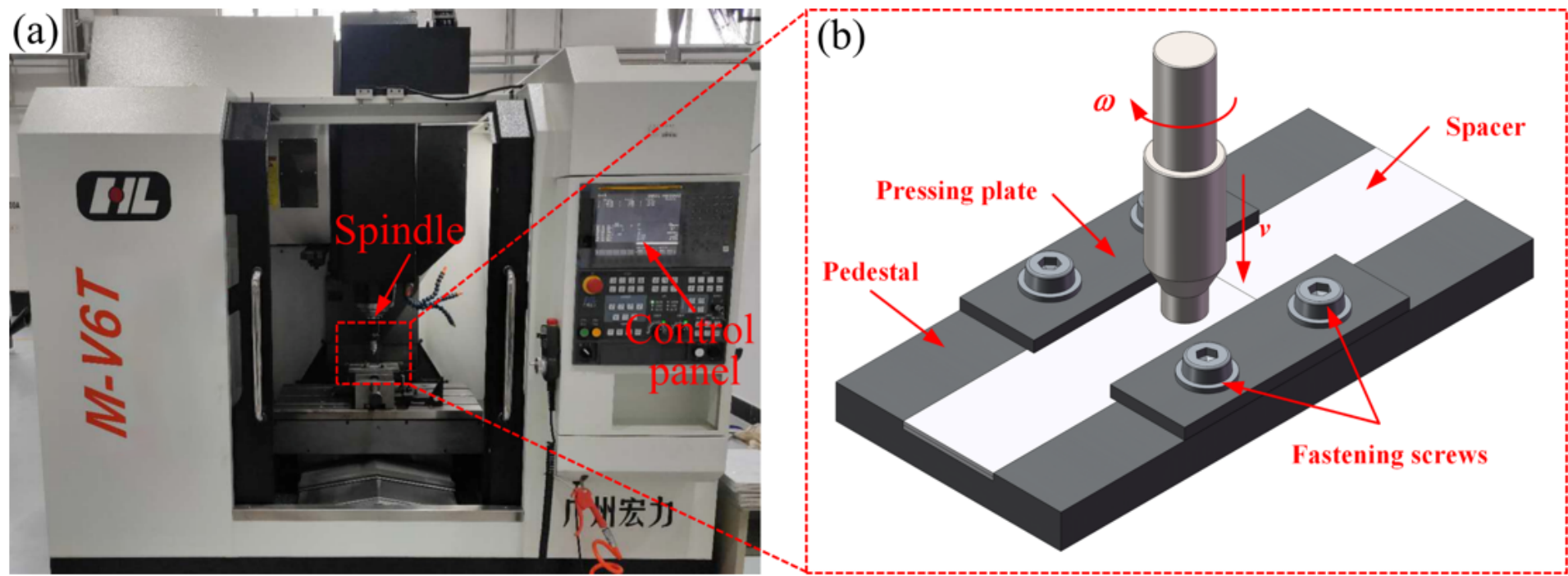
Figure 4

(a) probeless friction stir spot welding equipment and (b) schematic diagram of the experimental configuration.
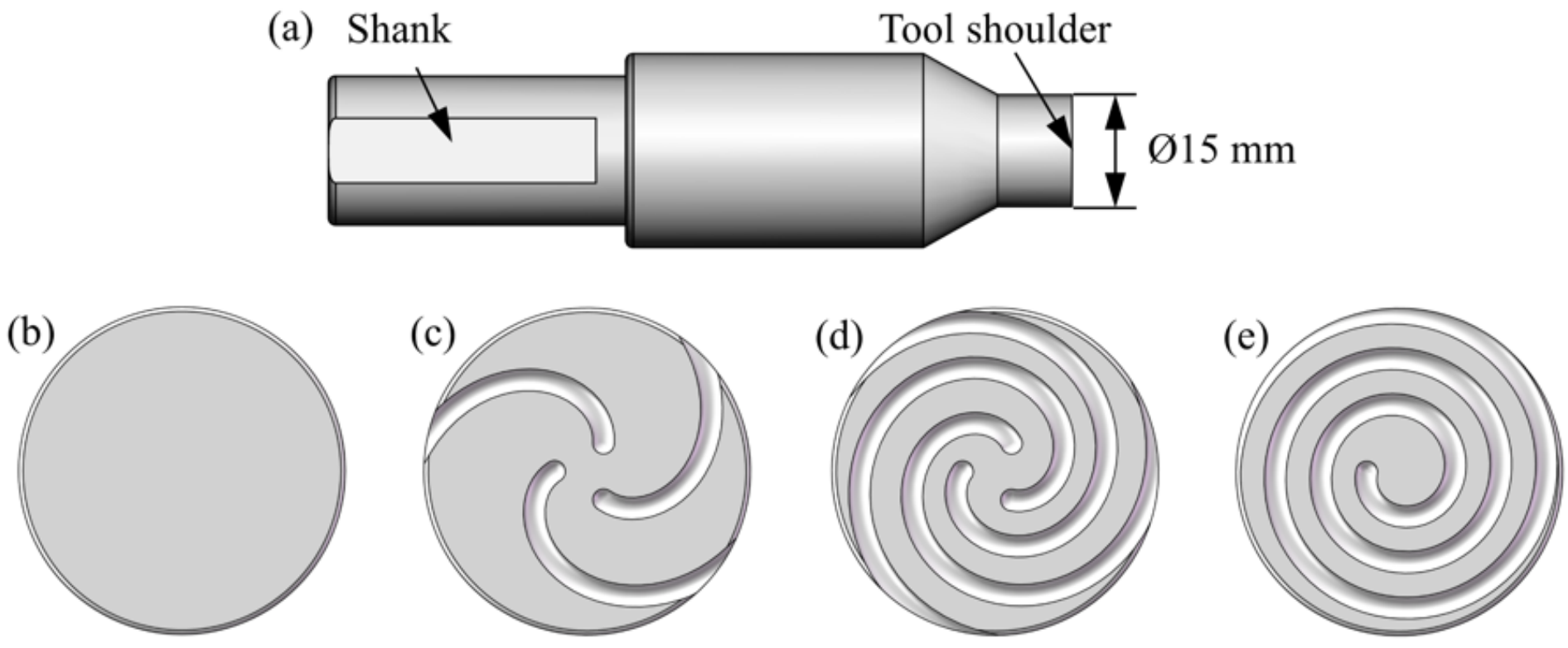

\section{Figure 5}

Welding tools for the four shoulder shapes: (a) side view of the probeless welding tool; bottom view of flat tool (b); archimedes tool (c); involute tool (d) and scroll tool (e).
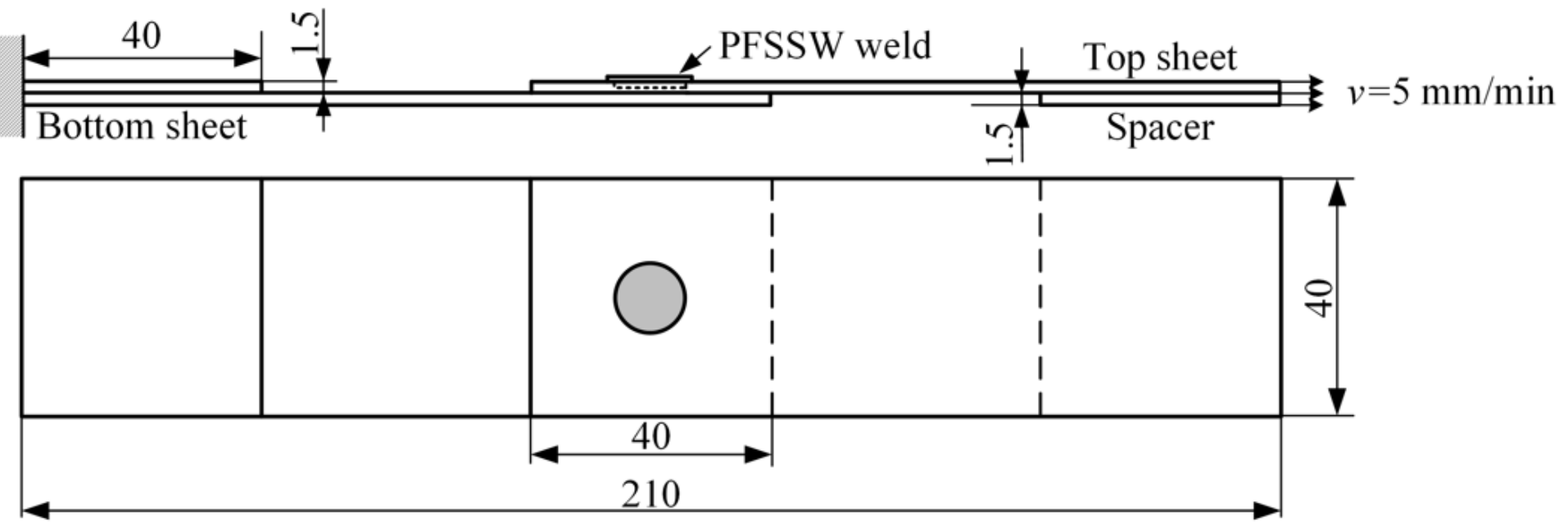

Figure 6

Schematic diagram of loading conditions for PFSSW welds in the tensile-shear configuration ( $\mathrm{mm})$. 

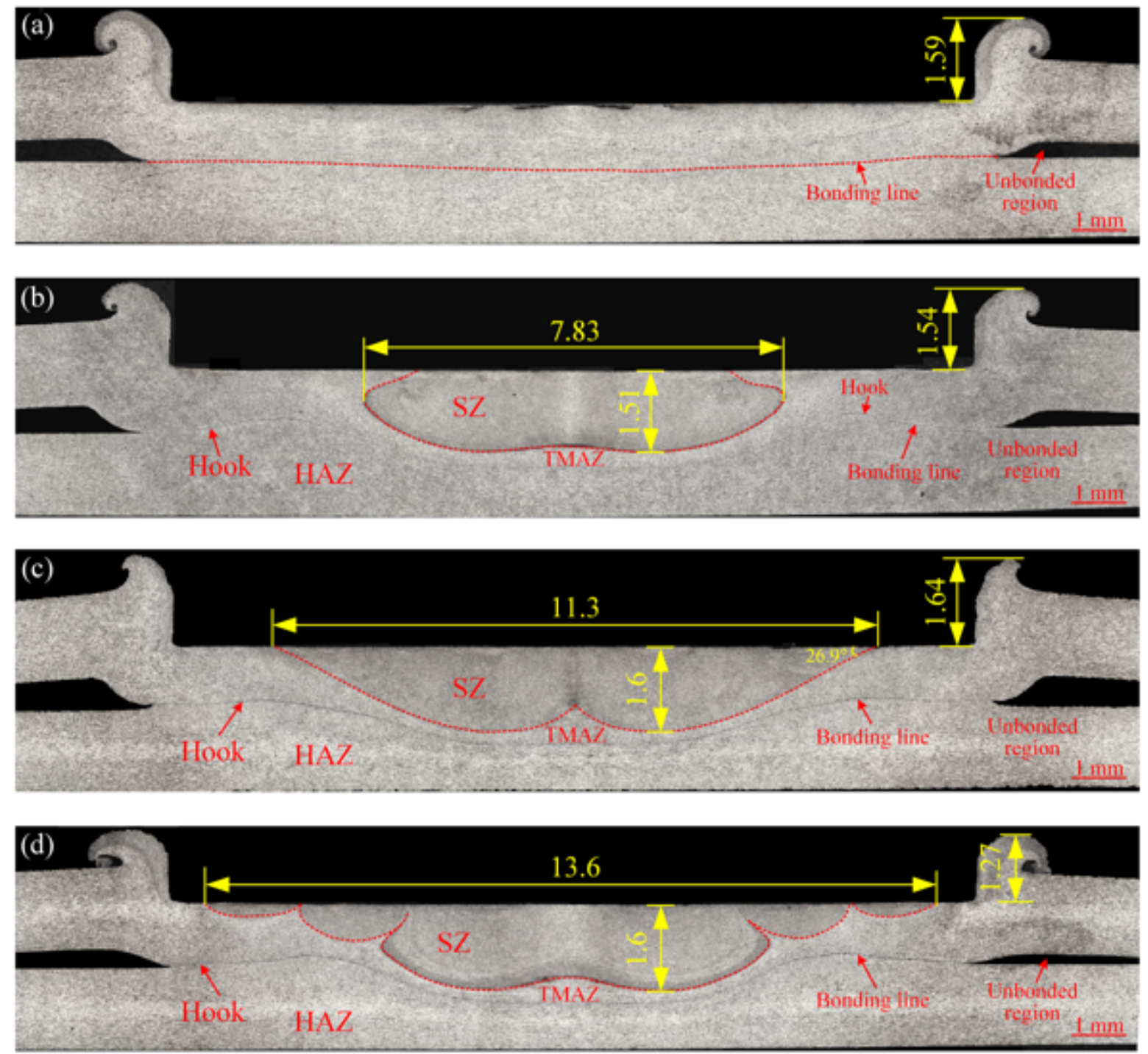

\section{Figure 7}

The cross-sectional microstructure of PFSSW joint for: (a) FT, (b) AT, (c) IT and (d) ST (RS=3000 rpm, $\mathrm{PD}=0.5 \mathrm{~mm}, \mathrm{DT}=5 \mathrm{~s})$.
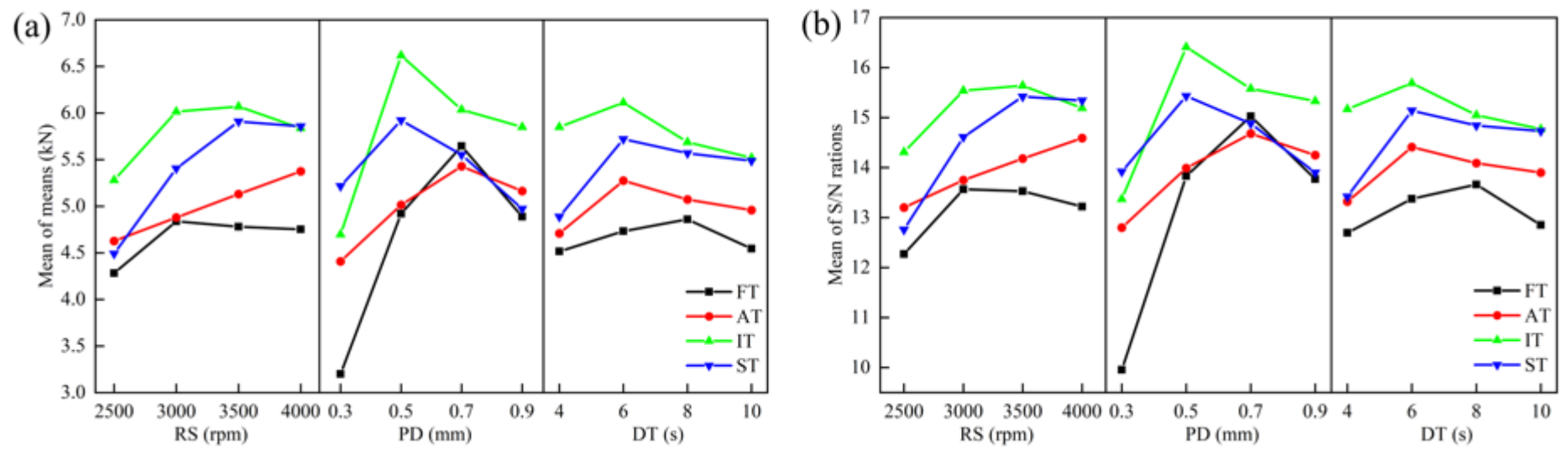

Figure 8 
Mean effects plot for the four shoulder shapes in PFSSW welds (a) mean of means, and (b) S/N rations.
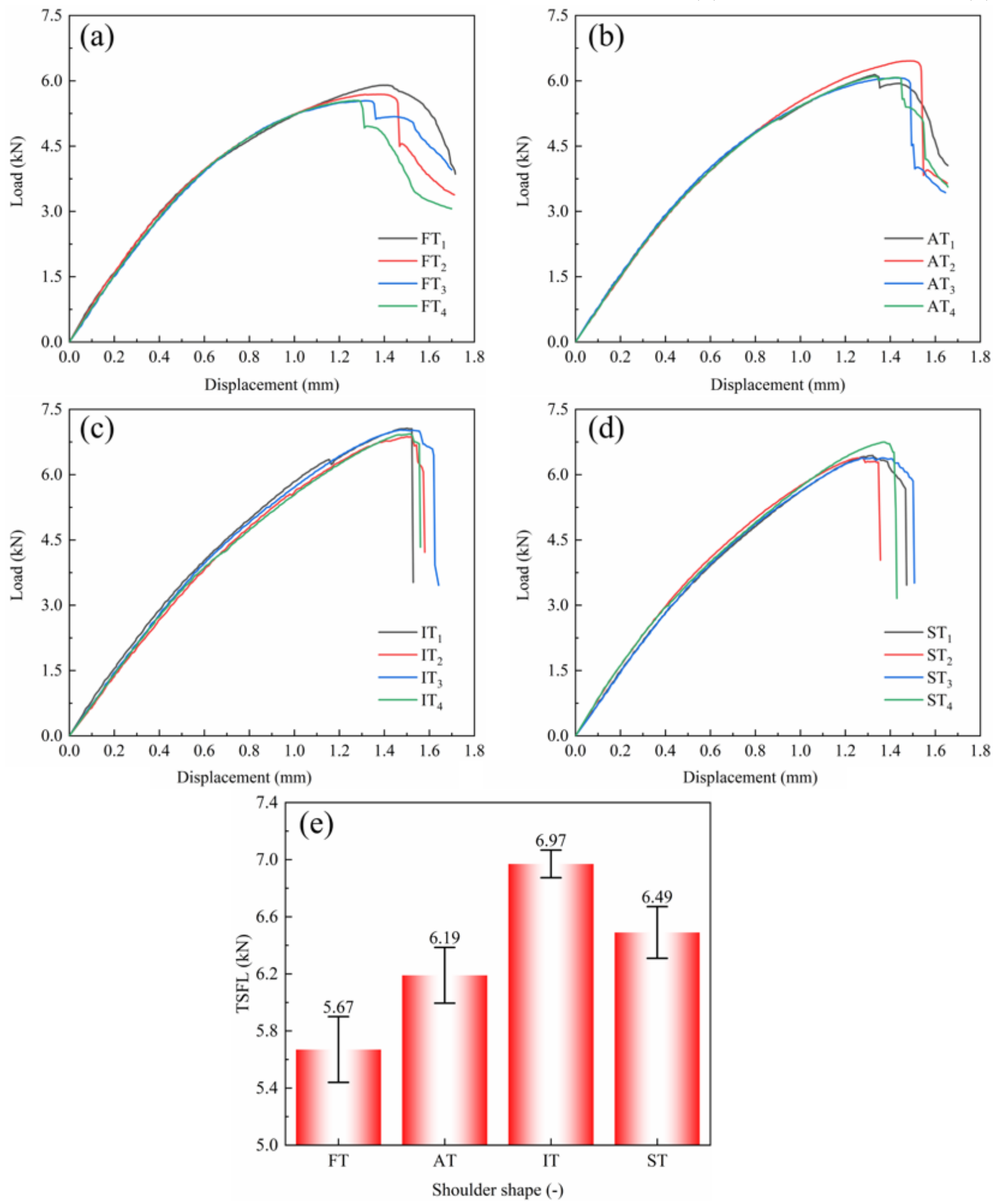

Figure 9

Tensile-shear mechanical behaviors for welds in the four shoulder shapes: (a) FT; (b) AT; (c) IT; (d) ST and (e) TSFL comparison. 
(a)

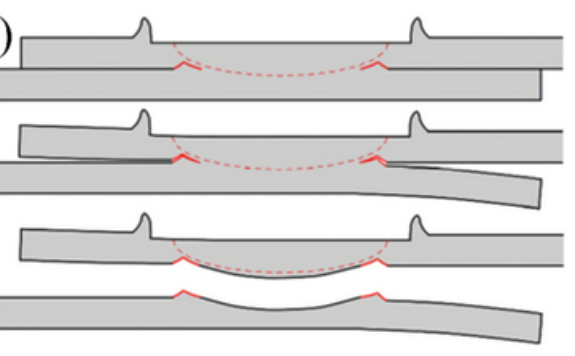

(b)

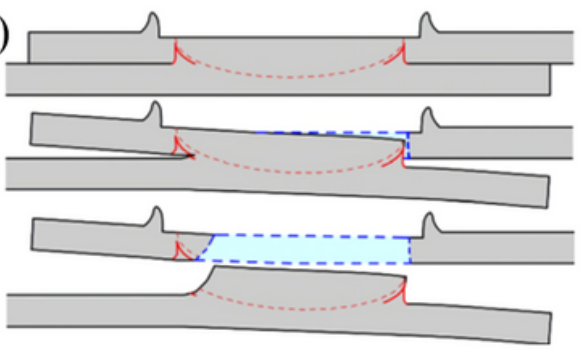

(c)

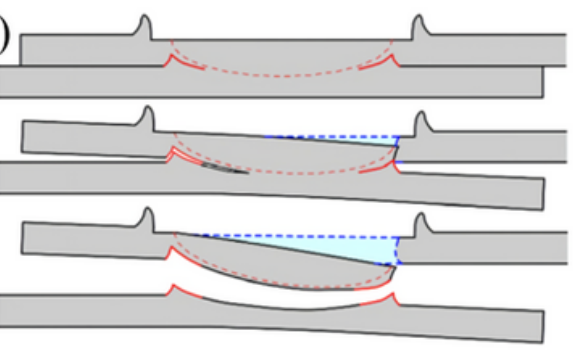

Figure 10

Fracture process of PFSSW welds: (a) interfacial fracture (mode I); (b) plug fracture (mode II) and (c) mixed-mode fracture (mode III) [32]. 

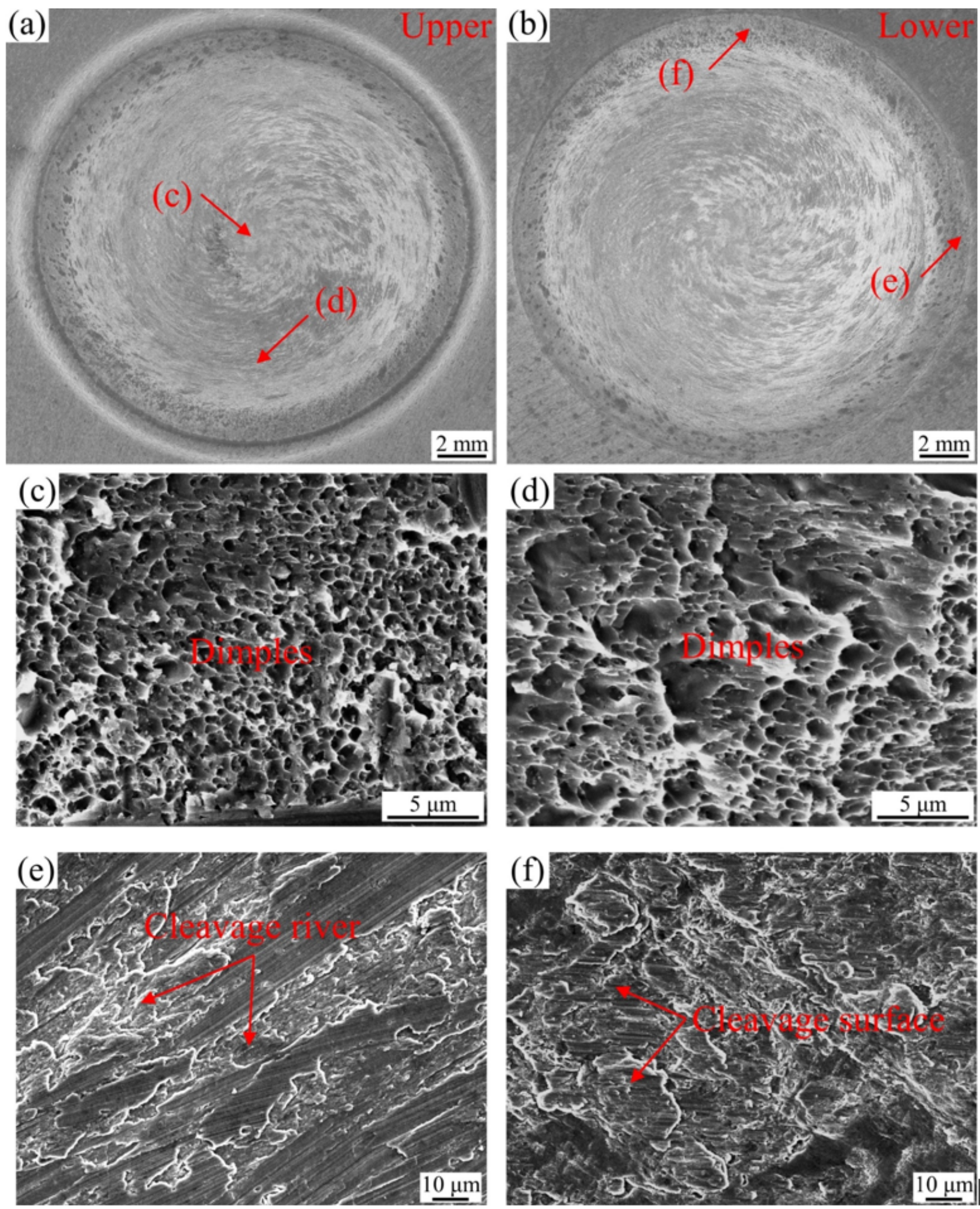

\section{Figure 11}

Fracture surface features of the PFSSW weld in mode l: (a) upper sheet of the weld, (b) lower sheet of the weld, center region (c) and marginal region (d) (magnification in Figure 11 (a)), right region (e) and bottom region (f) (magnification in Figure 11 (b)). 

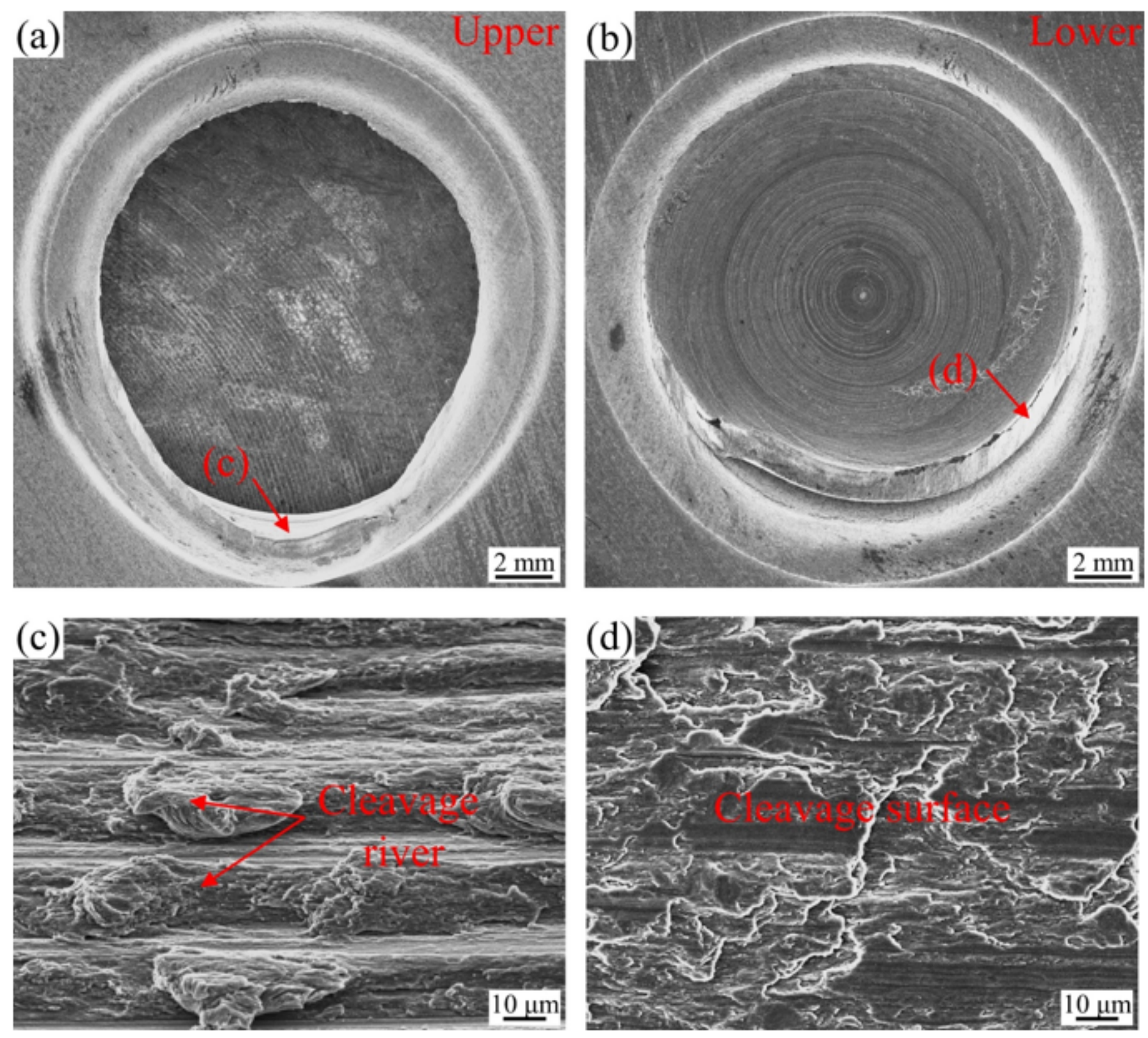

\section{Figure 12}

Fracture surface features of the PFSSW weld in mode II: (a) upper sheet of the weld, (b) lower sheet of the weld, (c) magnification of region (c) in Figure 12 (a), and (d) magnification of region (d) in Figure 12 (b). 

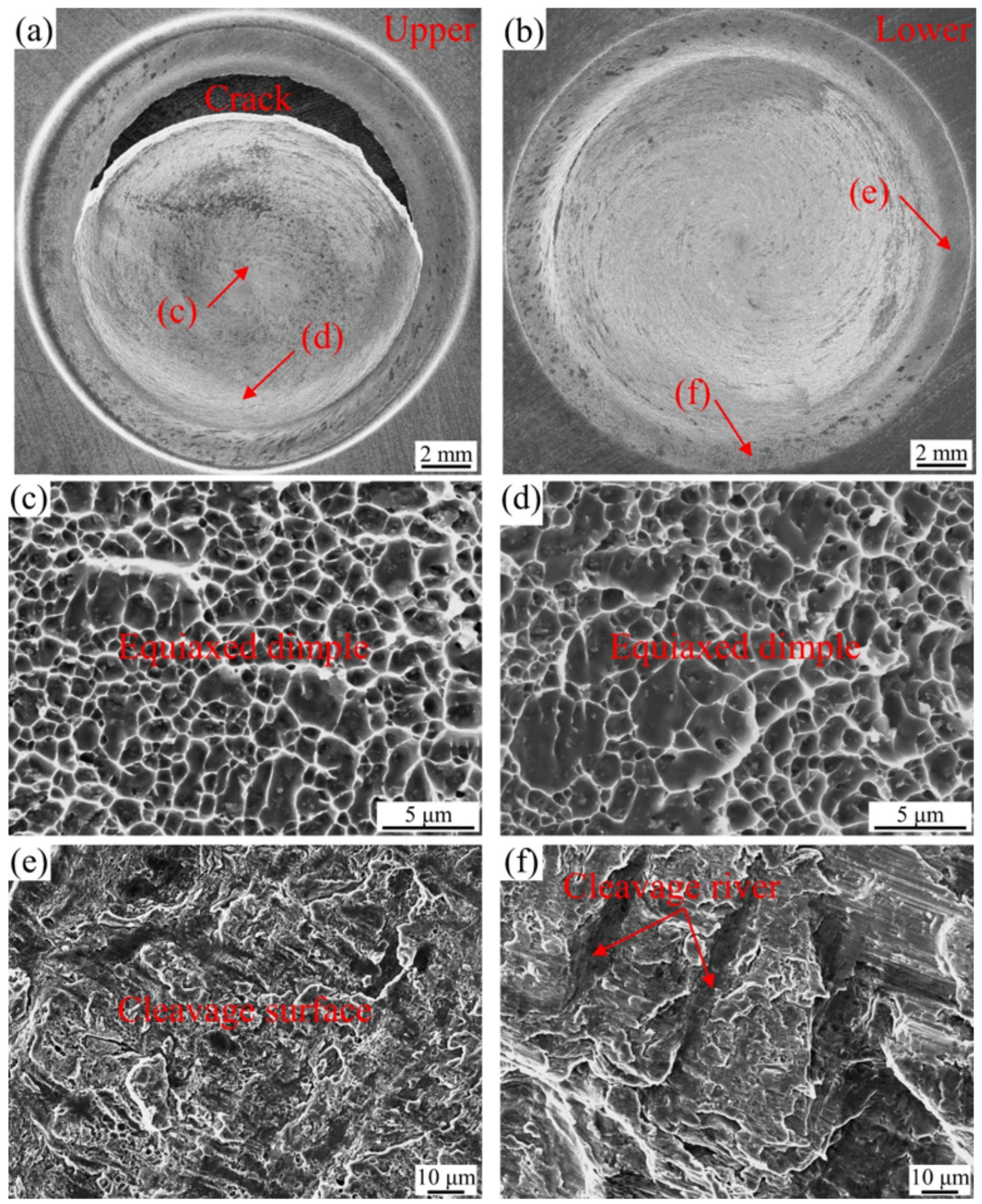

Figure 13

Fracture surface features of the PFSSW weld in mode III: (a) upper sheet of the weld, (b) lower sheet of the weld, center region (c) and marginal region (d) (magnification in Figure 13 (a)), right region (e) and bottom region (f) (magnification in Figure $13(b)$ ). 